УДК 621.791.052.8:622.692

ПОВЫШЕНИЕ БЕЗОПАСНОСТИ ПРИ ЭКСПЛУАТАЦИИ УЗЛОВ

ОТВЕТВЛЕНИЯ ТРУБОПРОВОДОВ С ПОМОЩЬЮ

УКРЕПЛЯЮЩИХ (НАКЛАДНЫХ) КОЛЕЦ

\title{
IMPROVING SAFETY DURING OPERATING PIPELETS \\ ANSWERING UNITS BY STRENGTHENING (FOLDING) RINGS
}

Яковлева Д.Н., Файрушин А.М., Исламова А.В.

Уфимский государственный нефтяной технический университет, Уфа, Российская Федерация

\author{
D.N. Yakovleva, A.M. Fairushin, A.V. Islamova \\ Ufa State Petroleum Technological University, Ufa, Russian Federation \\ e-mail: tna_ugntu@mail.ru
}

Аннотация. Одной из актуальных проблем обеспечения безопасности работы нефтегазохимического комплекса является повышение прочности и надежности трубопроводной системы. $\mathrm{K}$ особо опасным участкам трубопроводной системы относятся ответвления и врезки. Решение данной задачи повысит уровень промышленной безопасности эксплуатации трубопроводов. Напряженно-деформированное состояние рассматриваемых участков трубопровода требует повышенного контроля и внимания. К причинам напряженно-деформированного состояния относятся условия работы трубопроводной системы, постоянные нагрузки, среда в трубах, наличие коррозионной защиты и дефектных зон.

В данной работе анализируется один из главных способов укрепления мест ответвления трубопровода - укрепление усиливающими накладками, указываются преимущества и недостатки применения усиливающих накладок. Анализ способов укрепления ответвления трубопровода показал 
распространенность использования плоских накладок, но сложности заключается в технологии сборки и приварки усиливающих накладок.

Для увеличения надежности мест ответвления трубопровода в работе предлагается использование двух усиливающих накладок, уложенных послойно. Накладки имеют толщину, в сумме дающую толщину одной накладки, предлагаемую по отраслевым стандартам. Моделирование с использованием численных методов показывает целесообразность данного конструктивного решения. При использовании двух накладок уровень напряжений в узле ниже по сравнению с одной усиливающей накладкой. Обоснован вывод об увеличении ресурса работы и снижении вероятности разрушения узлов с двумя накладками.

Abstract. One of the urgent problems of ensuring the safety of the petrochemical complex is to increase the strength and reliability of the pipeline system. Branches and tie-ins are particularly dangerous sections of the pipeline system. The solution of this problem will increase the level of industrial safety of pipelines operation. The stress-strain state of the pipeline sections considered requires increased control and attention. The reasons for the stress-strain state include the operating conditions of the pipeline system, constant loads, the environment in the pipes, the presence of corrosion protection and defective zones.

In this paper, we analyze one of the main ways to strengthen pipeline branching sites - reinforcement with reinforcement plates, and indicate the advantages and disadvantages of using reinforcement plates. Analysis of ways to strengthen the branch pipe showed the prevalence of the use of flat linings, but the difficulty lies in the technology of assembly and welding of reinforcement linings.

To increase the reliability of pipeline branch points in the work, it is proposed to use two reinforcing plates laid in layers. The plates have a thickness of, in total, giving the thickness of one pad offered by industry standards. Simulation using numerical methods shows the feasibility of this design 
solution. When using two pads, the level of stress in the node is lower compared to a single reinforcing plate. The conclusion about the increase in the service life and reducing the probability of destruction of nodes with two plates is substantiated.

Ключевые слова: усиливающая накладка, ответвление, врезка, трубопровод, трубопроводная система, тройниковое соединение

Key words: reinforcing plate, branch, tie-in, pipeline, pipeline system, T-joint connection

На сегодняшний день остаются нерешенными задачи обеспечения достаточной прочности и надежности мест ответвления и врезки трубопровода. Несмотря на современные способы диагностики дефектов трубопровода и повышенный контроль технического состояния оборудования, остаются проблемы с так называемыми опасными участками трубопровода, такими как врезки и ответвления, переходами поперечного сечения.

На сегодняшний день используется большое количество видов конструкций ответвления (тройниковое соединение). Все они направлены на повышение надежности и прочности соединения трубопровода. Тройники претерпевают значительные напряжения от резкой смены параметров, как статические так и динамические. Сварные соединения тройников $\mathrm{c}$ трубопроводной системой в процессе эксплуатации испытывают различные по характеру нагрузки, которые появляются при изменении внутреннего давления в трубопроводе, колебаниях температуры окружающего воздуха и сдвигах грунта. На основании факторов, влияющих на прочность врезки или ответвления, создается конструкция тройника и выбирается технология его изготовления. Качество деталей трубопровода находится под строгим контролем. При нарушении технологии сварочного процесса создаются области повышенной 
концентрации напряжений, что может привести к разрушению трубопровода. По данным работы [1], интенсивность отказов на тройниках выше, чем на движущемся оборудовании, например вентилях и вращающихся деталях насоса.

Для укрепления конструкции тройники усиливают специальными накладками. Для сравнения - коэффициент концентрации в узле ответвления для тройника без усиливающей накладки $\mathrm{K}_{\sigma}=3,72$, a для тройника с усиливающей накладкой $\mathrm{K}_{\sigma}=1,5$ [2].

Применяемые накладки бывают различных типов (рисунок 1).

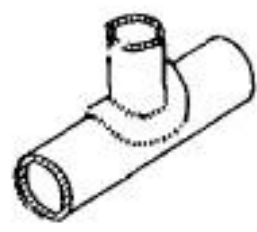

a

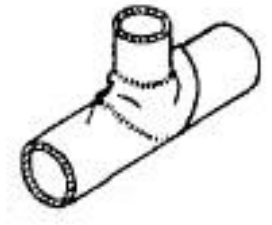

6

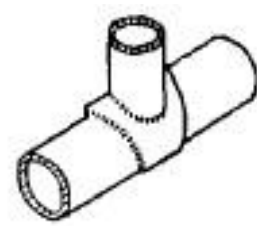

B

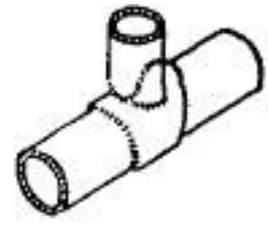

r
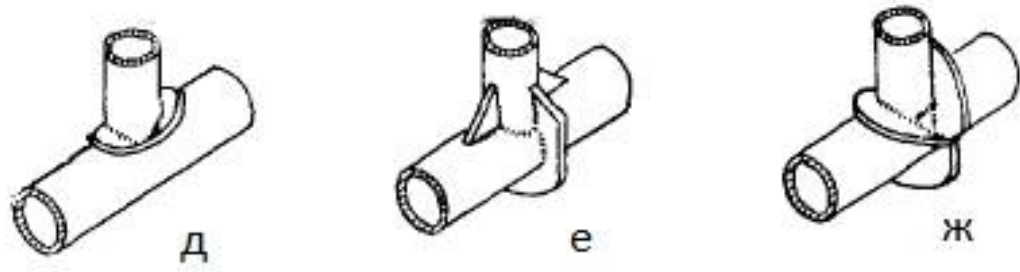

а) плоские; б) воротник; в) плоские, охватывающие всю трубу;

г) заплечики; д) кольцевая накладка в виде воротника;

е) косынки и ребро; ж) три ребра

Рисунок 1. Виды усиливающих накладок [1]

Наиболее часто используется технология укрепления ответвления с помощью плоских накладных колец.

Прочность на разрыв тройниковых соединений доводится до прочности основной трубы благодаря накладным кольцам (накладкам). Однако у накладок отсутствует противодействие раннему возникновению пластических деформаций, а значит, они не являются оптимальным средством, которое дает возможность повышения давления в месте соединения труб без появления текучести в отдельных зонах сопряжения. 
Сварные швы для воротниковых соединений могут превысить местное напряженное состояние выше значений предела усталости, предела текучести и предела прочности.

Недостатком использования усиливающих накладок является сложность пригонки, сборки и приварки накладки [3, 4].

В отчетах об аварийных ситуациях, происходивших на магистральных трубопроводах, говорится о том, что одной из возможных причин аварии является приварка к патрубкам неравнокатетными швами [5]. В нормативной документации указано об обязательных требованиях исполнения равнокатетных швов. Появление трещины в месте врезки и ответвления трубопровода также не редкий случай при обследовании участков магистрального трубопровода.

На сегодняшний день широко используется технология повышения прочности и надежности мест врезки трубопровода с помощью усиливающей накладки (укрепляющего кольца). Применение укрепляющих накладок регламентируется различными нормативными документами, в том числе ГОСТ 32569-2013 и СТО Газпром 2-2.3-1162007.

СТО Газпром 2-2.3-116-2007 нормирует размеры толщин стенок врезаемых труб в зависимости от трубопровода. Толщину накладного кольца в узлах принимают в 1,25 раз больше, чем толщина стенки трубопровода. Если толщина накладки равна толщине стенки трубы, то наружный диаметр накладки принимается в 2,0 раза больше, чем диаметр трубопровода-отвода. При толщине стенки усиливающей накладки в 1,25 раза больше толщины стенки трубопровода ширина накладки принимается 0,09 м. На поверхности трубы монтируют накладку с допустимым зазором между поверхностью трубы и кольца от 0 до 2 мм.

Требования стандарта описывают использование одной усиливающей накладки. Геометрия и конструкция накладки описаны в отраслевом стандарте, однако при приварке усиливающей накладки к трубе в металле 
трубы формируется объемная зона термического влиянии, имеющая пониженные прочностные свойства и склонная к появлению трещин.

Помимо усиливающей накладки существуют и другие варианты усилений узла врезки. Для подземного трубопровода с тройниковым соединением предлагается использовать стабилизирующее устройство [4], а также сильфонные компенсаторы.

В литературе описаны возможные причины аварий на магистральных трубопроводах и проведены обширные исследования трубопроводов, подвергшихся появлению дефектов и возникновению аварии [5]. Так как ответвления и места врезки относятся к участкам, работающим в сложных условиях с изменением направления потока, то безопасность эксплуатации должна быть соблюдена в соответствие с нормативными документами, например РД 38.13.004-86 или ПБ 03-585-03. В данных документах говорится, что ответвления не допускается укреплять косынками или ребрами жесткости, так как этот способ сложный по сварке и трудный для радиографической диагностики дефектов. Этот способ в основном применяется для укрепления штуцеров в сосудах и аппаратах [6].

Аварийные участки и дефекты ответвлений указывают на основные причины разрушения узла трубопровода:

- высокая концентрация напряжений. Сварное соединение, включающее угловой сварной шов для приварки накладки, может повысить напряжение на переходе от шва к поверхности трубы в 3 и более pa3;

- циклический характер нагрузки [7];

- действие агрессивной среды в трубах на структуру металла;

- изменение механических свойств металла трубопровода и сварных соединений;

- значительная зона термического влияния шва;

- накопленные дефекты в процессе эксплуатации [1];

- условия эксплуатации трубопровода; 
- зазоры между усиливающей накладкой и корпусом трубопровода [3].

По результатам анализа технологии изготовления и монтажа накладных колец предлагается уменьшить величину сварного шва и соответственно зоны термического влияния путем уменьшения толщины самих накладок (рисунок 2).

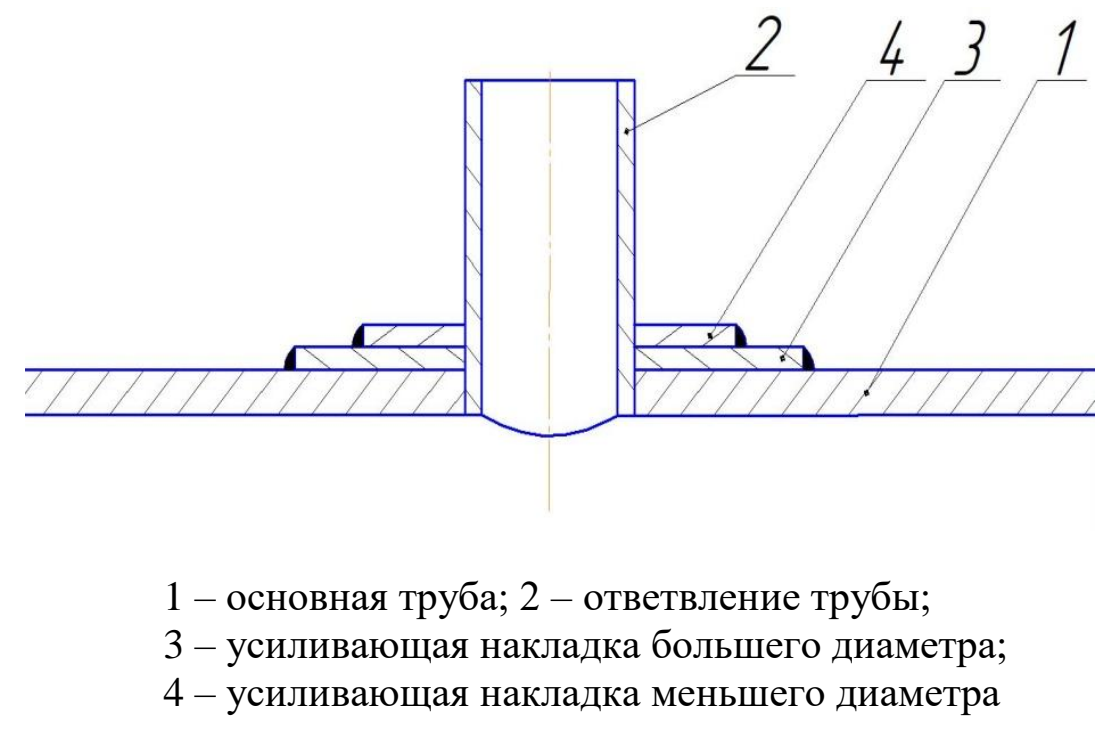

Рисунок 2. Схема тройника сварного с использованием двух усиливающих накладок

При использовании двухслойной конструкции кольца можно снизить величину зазора между накладкой и корпусом. При снижении толщины пластины зона термического влияния в металле трубы значительно уменьшиться, что подтверждают проведенные практические исследования на натурных образцах пластин.

Макроструктура натурных образцов соединений укрепляющих колец с корпусом (рисунок 3) показывает, что у модели с кольцом толщиной 10 мм зона термического влияния значительно больше, чем у кольца толщиной 5 мM. 

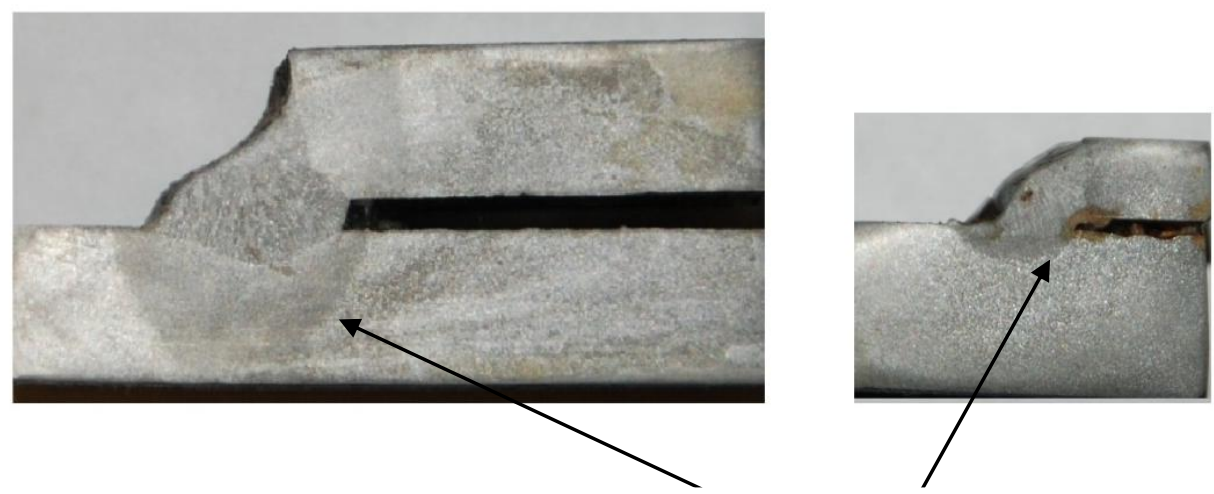

Зона термического влияния

Рисунок 3. Зона термического влияния на модельных образцах

С целью определения и сравнения напряженно-деформированного состояния в узле при использовании различных конструктивных исполнений накладок были проведены численные исследование на моделях в программе ANSYS WORCKBENCH в модуле Static Structural.

Прикладываемые нагрузки:

pressure: $2 \mathrm{M \Pi а;}$

displacement: $3 \mathrm{MM}$;

fixed support: торцы.

Модель представляла собой цилиндрическую трубу с врезанным ответвлением. Расчетные данные модели приведены в таблице 1.

Таблица 1. Расчетные данные модели

\begin{tabular}{|l|c|c|}
\hline \multicolumn{1}{|c|}{ Показатель } & Единица & Значение \\
\hline Наружный диаметр основного трубопровода & мм & 820 \\
\hline Толщина стенки основного трубопровода & мм & 11 \\
\hline Рабочее давление & МПа & 2,0 \\
\hline Температура & ${ }^{\circ} \mathrm{C}$ & 20 \\
\hline Наружный диаметр трубопровода-отвода & мм & 200 \\
\hline Толщина стенки трубопровода-отвода & мм & 10 \\
\hline
\end{tabular}

Место врезки и укрепления отверстия усиливалось двумя накладками, сумма толщин которых составляет толщину одиночного кольца для укрепления (рисунок 4). 

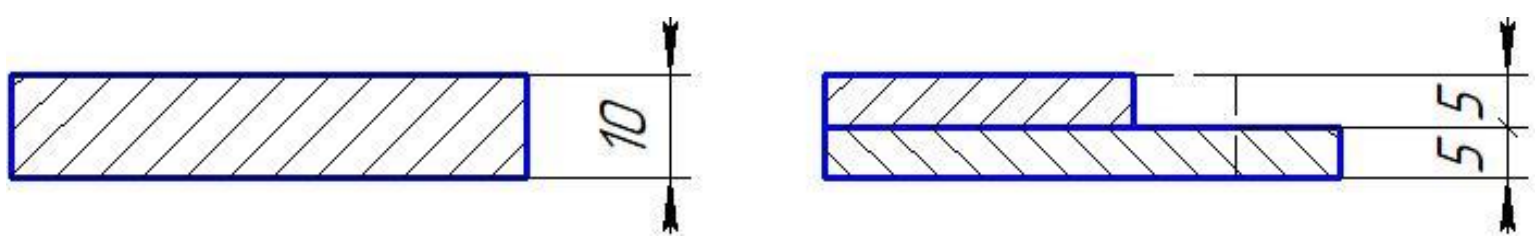

Рисунок 4. Одна накладка и послойный вариант укрепления ответвления

Для проведения выбора оптимального варианта были рассмотрены модели с различными размерами усиливающих накладок.

Размеры усиливающих накладок:

модель 1 (350 мм/ 450 мм, $\left.\mathrm{S}_{1}=\mathrm{S}_{2}=5 \mathrm{мм}\right)$;

модель 2 (350 мм/ 400 мм, $\mathrm{S}_{1}=\mathrm{S}_{2}=5$ мм (рисунок 5));

модель $3\left(300 \mathrm{mм} / 500 \mathrm{мм}, \mathrm{S}_{1}=\mathrm{S}_{2}=5 \mathrm{mм}\right)$.

Накладки имеют изгиб, равный диаметру основной трубы.

Сетка конечных элементов в зоне укрепления увеличена в разделе «Face Sizing» в «Mesh» для повышения точности моделирования и результатов (рисунок 6).

Модель трубопровода испытывает внутреннее давление в 2 МПа и перемещение трубопровода-отвода вдоль оси у на 0,003 м. Металл представлял собой материал с модулем упругости $\mathrm{E}=2 \cdot 10^{11}$ Па, коэффициентом Пуассона $v=0,3$ и пределом текучести 250 МПа (аналог сталь 10Г2).

Поля распределения эквивалентных напряжений, полученные в результате расчетов, представлены на рисунках 7-9. 


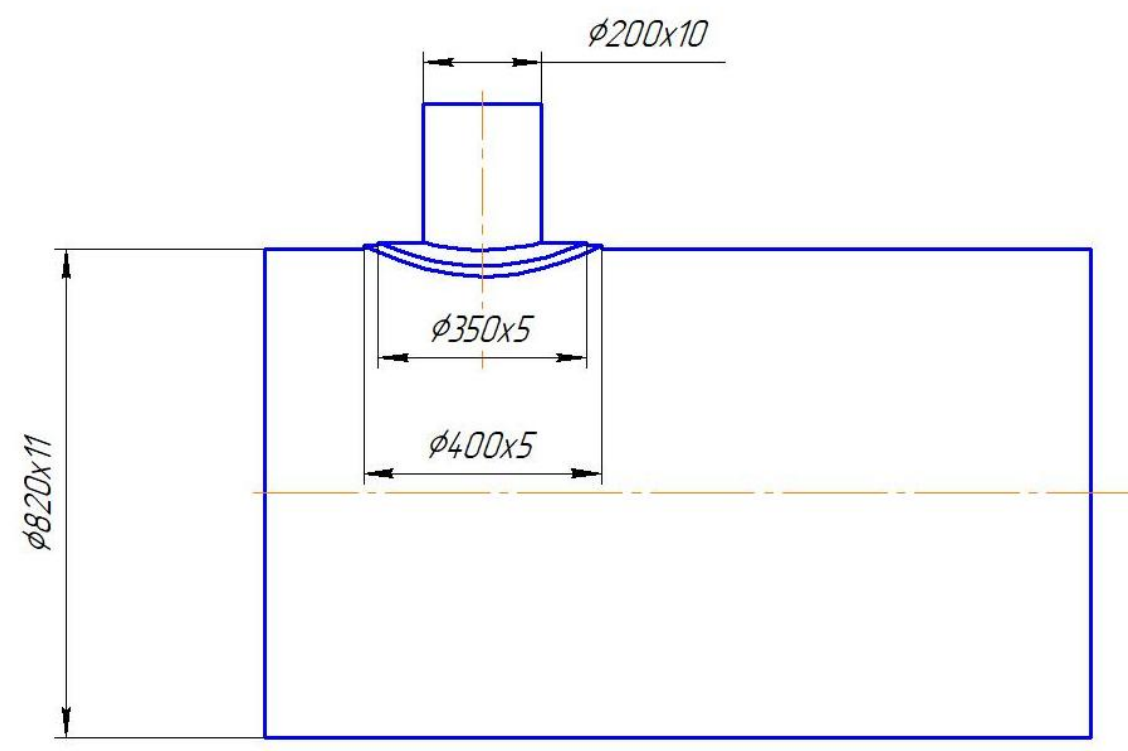

a)
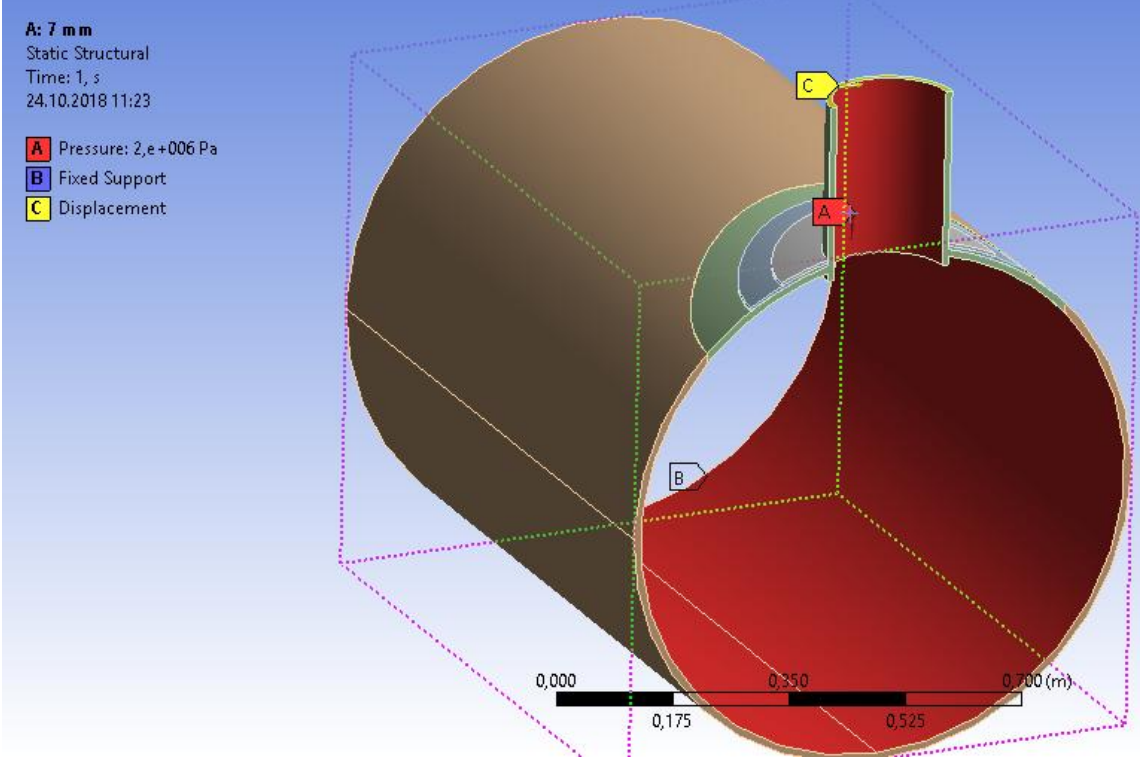

\section{ANSYS}

B Fixed Support

C Displacement

б)

a) размеры рассчитываемой конструкции на примере модели 2;

б) трехмерная модель с нагрузками и ограничениями на примере модели 2

Рисунок 5. Модель с применением усиливающих накладок 


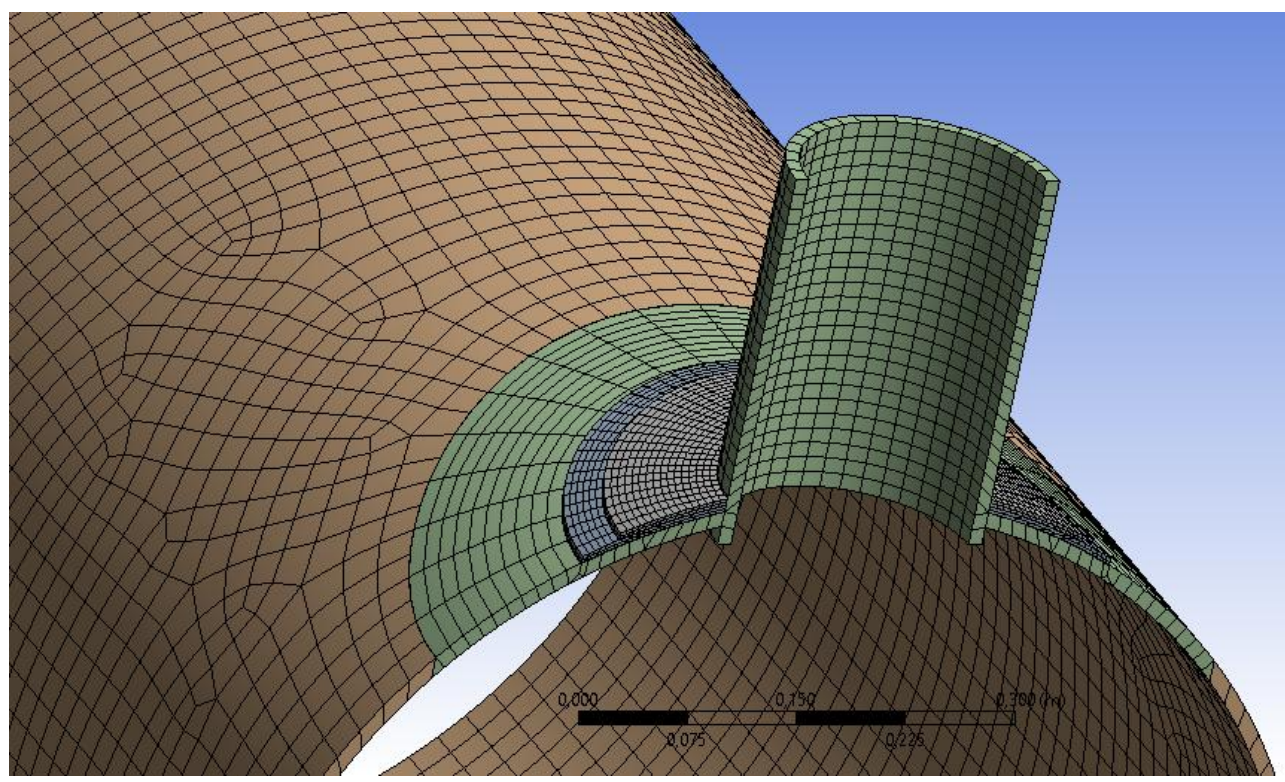

ANSYS

\section{Рисунок 6. Сетка конечных элементов}

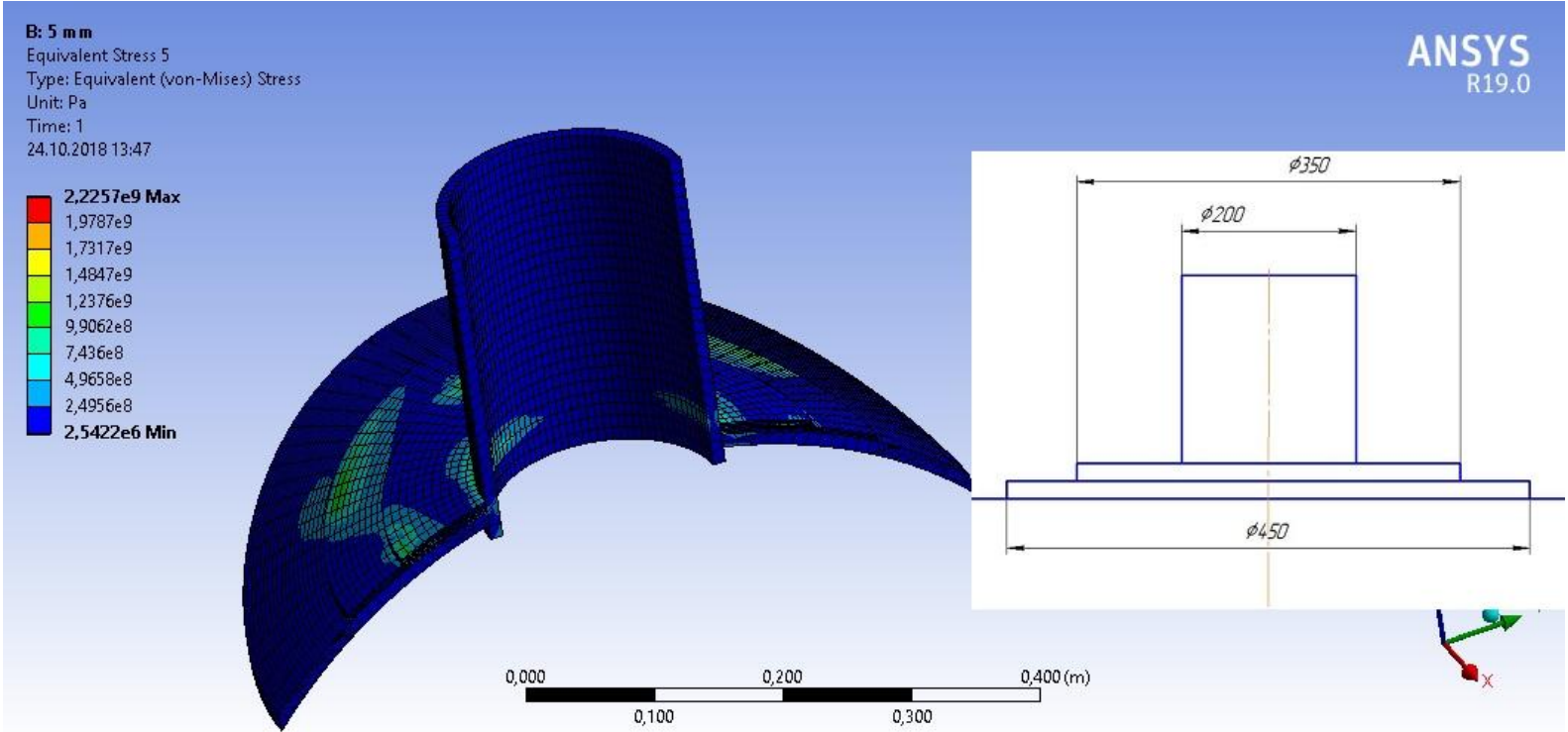

Рисунок 7. Поля распределения эквивалентных напряжений в модели № 1 


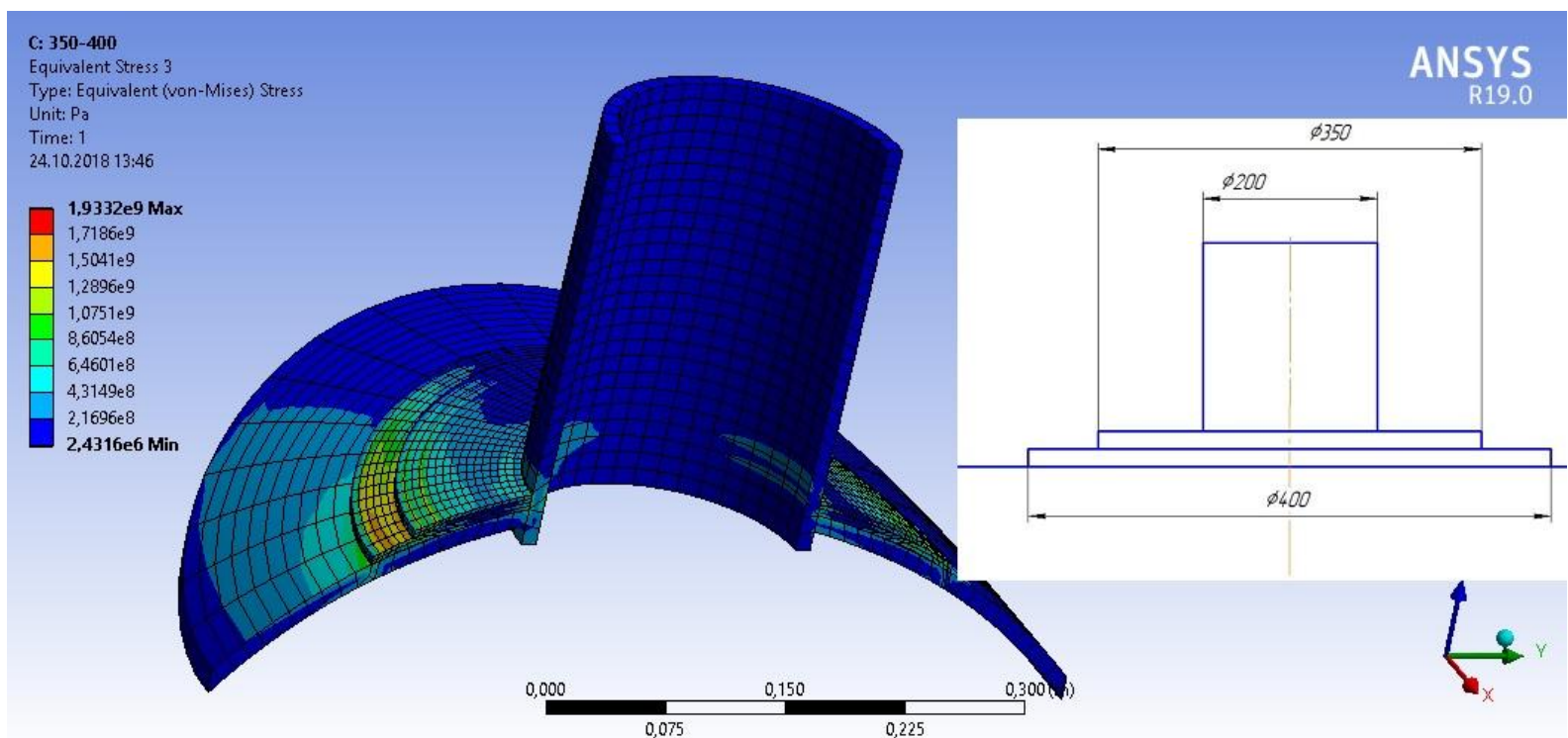

Рисунок 8. Поля распределения эквивалентных напряжений в модели № 2

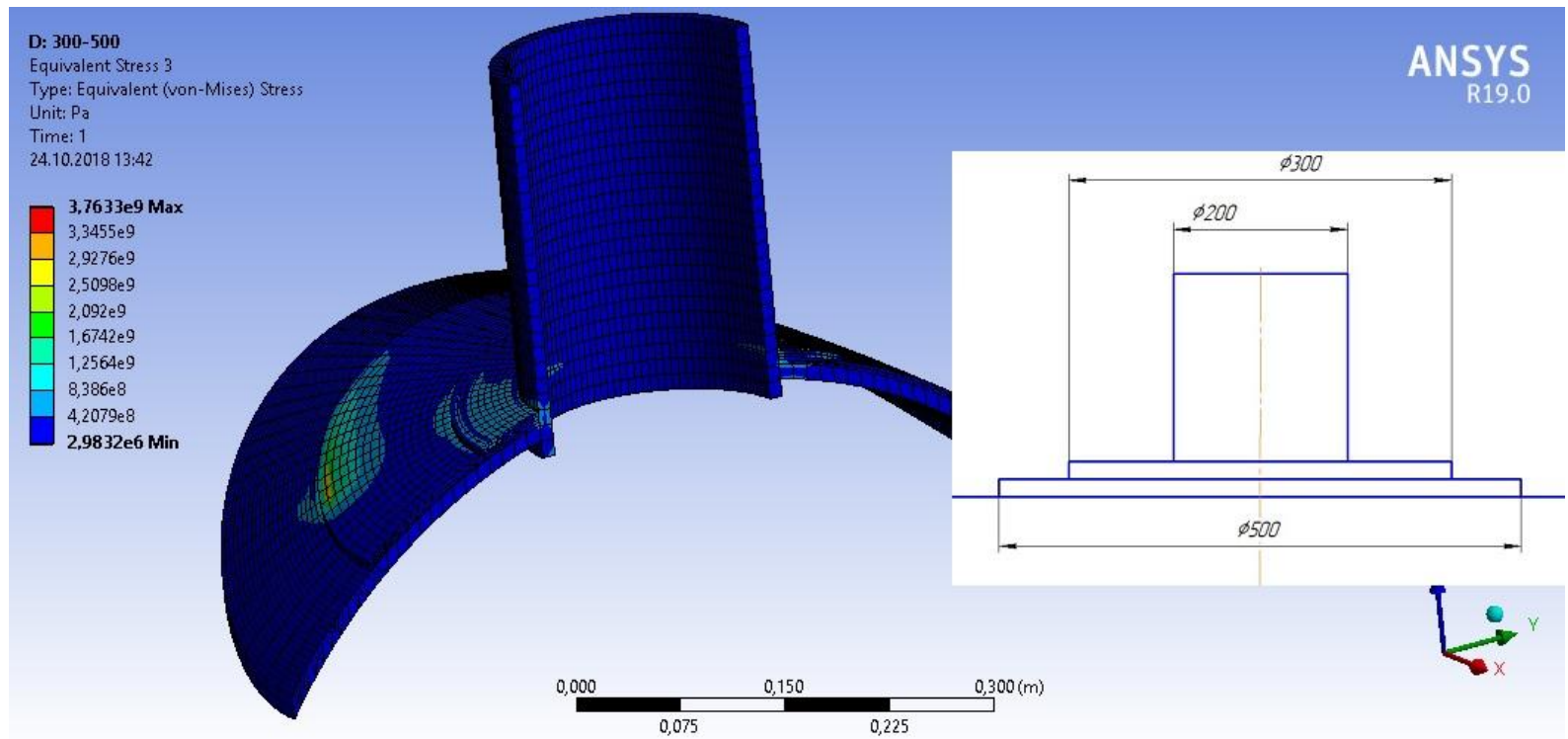

Рисунок 9. Поля распределения эквивалентных напряжений в модели № 3

Максимальные эквивалентные напряжения концентрируются на модели с одной накладкой в месте ответвления трубы (рисунок 10). 


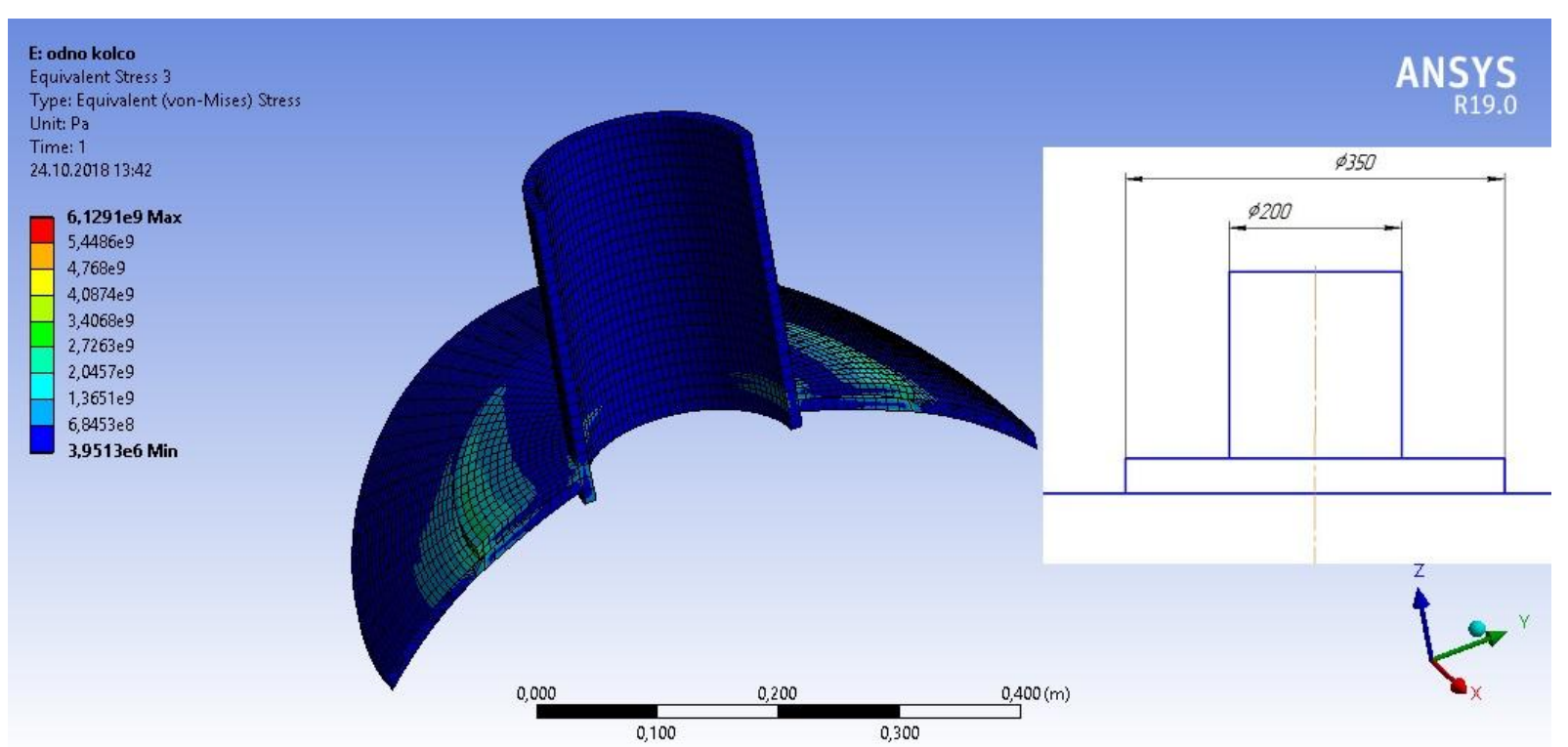

Рисунок 10. Модель с одной усиливающей накладкой

Для численного сравнения моделей построены графики действия эквивалентных напряжений в моделях, действующие вдоль наиболее нагруженного сечения узла. Уменьшаются напряжения на наружной поверхности и для зоны термического влияния. Расстояние от оси патрубка до зоны термического влияния указано точками на графике (рисунок 11) для соответствующих моделей.

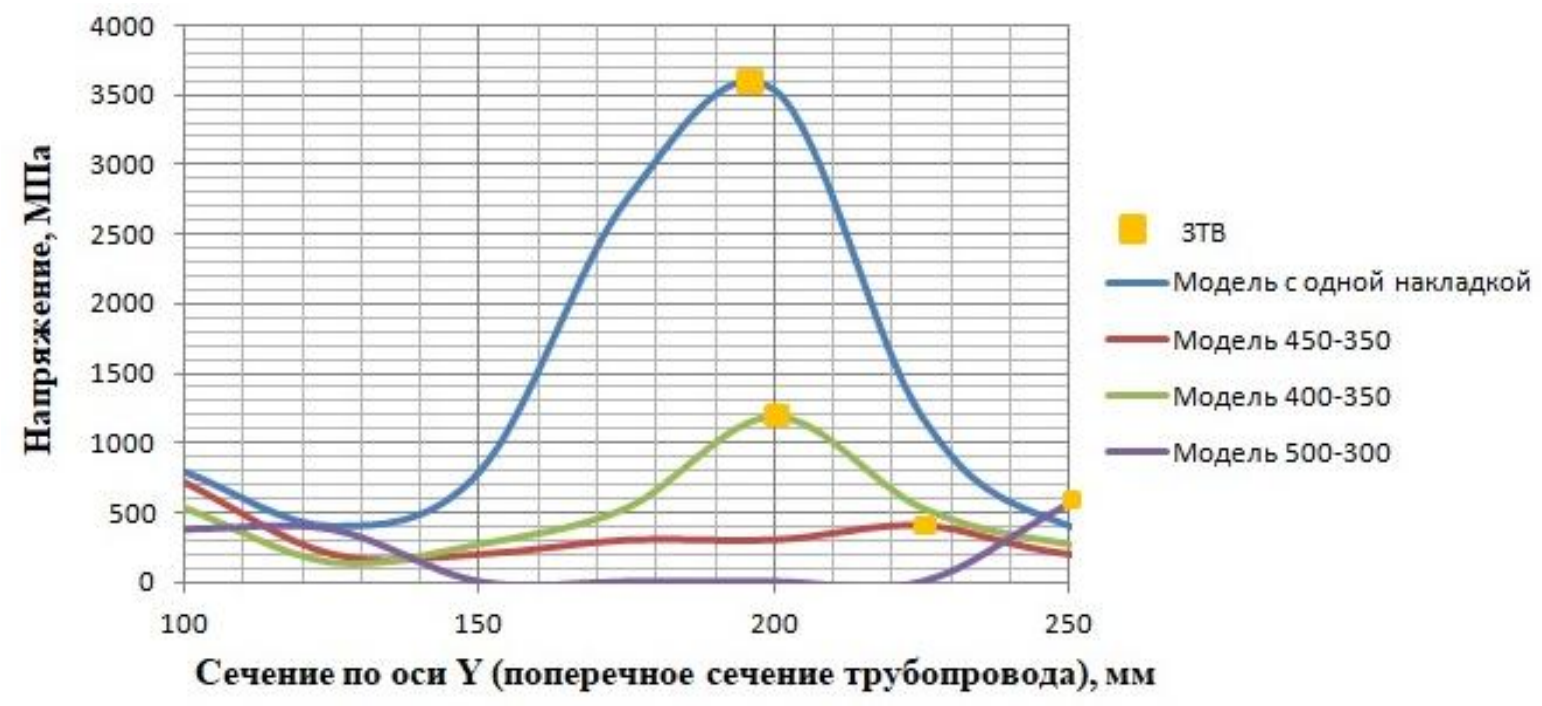

Рисунок 11. График изменения эквивалентных напряжений на наружной поверхности для различных конструктивных исполнений узла в поперечном сечении 
Как показывают результаты моделирования, применяемая на сегодняшний день конструкция является наиболее нагруженной для зоны термического влияния приварки накладки к корпусу. При использовании двухслойных накладок можно снизить уровень внутренних напряжений в опасном сечении практически на 30 \% при сохранении толщины накладки на том же уровне.

\section{Выводы}

1. Тройниковые соединения подвержены значительным нагрузкам, вследствие чего требуют особое внимание к качеству изготовления и минимизации негативного воздействия на тело трубы от сварки.

2. Повышение безопасности опасного участка ответвления и врезки достигается путем установки плоской усиливающей накладки на трубопроводе-отводе. Существующая технология усиления с помощью одной накладки, как показывает практика, не обеспечивает безопасную эксплуатацию ответвлений. Отчеты об авариях на магистральном трубопроводе указывают на недостаточное обеспечение прочности участков ответвлений.

3. На основании проведенного численного исследования на примере модели труба - отвод с двумя накладками, приваренными послойно, можно утверждать о снижении уровня напряжений в области приварки накладки к трубопроводу-патрубку.

\section{Список используемых источников}

1. Хасанов Р.Р., Султанмагомедов С.М. Напряженно-деформированное состояние и обеспечение надежности тройников подземных трубопроводов: монография. Уфа: Изд-во УГНТУ, 2013. 100 с.

2. Ерофеев В.В. Оценка остаточного ресурса сварных соединительных узлов магистральных трубопроводов на базе данных технической диагностики: сб. науч. тр. Челябинск, 2012. С. 24-31. 
3. Аписов И.В., Четверткова О.В., Каретников Д.В., Ибрагимов И.Г., Закиров Т.Э. Анализ напряженного состояния укрепленного накладным кольцом штуцерного узла с учетом дефектов сборки // Электронный научный журнал «Нефтегазовое дело». 2014. № 5. С. 223-237. URL: ogbus_5_2014_p223-237_ApisovIV_ru.pdf.

4. Пат. 96212 РФ, F 16 L 51/024. Стабилизатор механических напряжений / Р.Р. Хасанов, А.М. Шаммазов, С.М. Султанмагомедов, Ф.М. Мустафин. № 2010107996/22; Заявлено 04.03.2010; Опубл. 20.07.2010, Бюл. 20.

5. Гумеров А.К., Шмаков А.К., Хайрутдинов Ф.Ш. Механизмы разрушения магистральных трубопроводов с приварными элементами // Электронный научный журнал «Нефтегазовое дело». 2007. № 1. С. 1-5. URL: http://ogbus.ru/files/ogbus/authors/GumerovAK/GumerovAK_1.pdf.

6. Файрушин А.М., Зарипов М.З., Каретников Д.В, Яковлева Д.Н., Исламова А.В. Разработка рекомендаций по применению локально укрепленных штуцерных узлов с ребрами жесткости // Электронный научный журнал «Нефтегазовое дело». 2017. № 6. С. 76-95. URL: http://ogbus.ru/files/ogbus/issues/6_2017/ogbus_6_2017_p76-

95_FairushinAM_ru.pdf.

7. Гумеров А.Г., Гумеров Р.С., Гумеров К.М. Безопасность длительно эксплуатируемых магистральных нефтепроводов. М.: Недра-Бизнесцентр, 2003. $310 \mathrm{c}$.

\section{References}

1. Khasanov R.R., Sultanmagomedov S.M. Napryazhenno-deformirovannoe sostoyanie $i$ obespechenie nadezhnosti troynikov podzemnykh truboprovodov [Stress-Strain State and Ensuring the Reliability of Tees Underground Pipelines]. Ufa, Izd-vo UGNTU, 2013. 100 p. [in Russian]. 
2. Erofeev V.V. Otsenka ostatochnogo resursa svarnykh soedinitel'nykh uzlov magistral'nykh truboprovodov na baze dannykh tekhnicheskoy diagnostiki: sb. nauch. tr. [Assessment of the Residual Life of Welded Connecting Nodes of Pipelines Based on Technical Diagnostics Data: Collection of Scientific Papers] Chelyabinsk, 2012, pp. 24-31. [in Russian].

3. Apisov I.V., Chetvertkova O.V., Karetnikov D.V., Ibragimov I.G., Zakirov T.E. Analiz napryazhennogo sostoyaniya ukreplennogo nakladnym kol'com shtucernogo uzla s uchetom defektov sborki [Analysis of the Stress State of a Choke Assembly Reinforced with a Patch Ring, Taking into Account Assembly Defects]. Elektronnyi nauchnyi zhurnal «Neftegazovoe delo» Electronic Scientific Journal «Oil and Gas Business», 2014, No. 5, pp. 223-237. [in Russian]. URL: ogbus_5_2014_p223-237_ApisovIV_ru.pdf.

4. Khasanov R.R., Shammazov A.M., Sultanmagomedov S.M., Mustafin F.M. Stabilizator mekhanicheskih napryazhenij [Mechanical Stress Stabilizer]. Patent RF, No. 96212, 2010. [in Russian].

5. Gumerov A.K., Shmakov A.K., Khayrutdinov F.S. Mekhanizmy razrusheniya magistral'nykh truboprovodov $s$ privarnymi ehlementami [Destruction Mechanisms of Trunk Pipelines with Welded Elements]. Elektronnyi nauchnyi zhurnal «Neftegazovoe delo» - Electronic Scientific Journal «Oil and Gas Business», 2007, No. 1, pp. 1-5. URL: http://ogbus.ru/files/ogbus/authors/GumerovAK/GumerovAK_1.pdf. [in Russian].

6. Fairushin A.M., Zaripov M.Z., Karetnikov D.V, Yakovleva D.N., Islamova A.V. Razrabotka rekomendatsij po primeneniyu lokal'no ukreplennykh shtutsernykh uzlov s rebrami zhestkosti [Development of Recommendations for the Use of Locally Reinforced Choke with Stiffening Ribs]. Elektronnyi nauchnyi zhurnal «Neftegazovoe delo» - Electronic Scientific Journal «Oil and Gas Business», 2017, No. 6, pp. 76-95. URL: http://ogbus.ru/files/ogbus/issues/6_2017/ogbus_6_2017_p76-95_FairushinAM _ru.pdf. [in Russian]. 
7. Gumerov A.G., Gumerov R.S., Gumerov K.M. Bezopasnost' dlitel'noekspluatiruemykh magistral'nykh nefteprovodov [Safety of Main Oil Pipelines after Prolong Operation]. Moscow, Nedra Publ., 2001. 305 p. [in Russian].

\section{Сведения об авторах}

\section{About the authors}

Яковлева Д.Н., магистрант кафедры «Технология нефтяного аппаратостроения», ФГБОУ ВО «УГНТУ», г. Уфа, Российская Федерация

D.N. Yakovleva, Undergraduate Student of Technology of Petroleum Apparatus Construction Department, FSBEI HE «USPTU», Ufa, Russian Federation

e-mail: dashkayakov@mail.ru

Файрушин А.М., канд. техн. наук, доцент, доцент кафедры «Технология нефтяного аппаратостроения», ФГБОУ ВО «УГНТУ», г. Уфа, Российская Федерация

A.M. Fairushin, Candidate of Engineering Sciences, Associate Professor, Assistant Professor of Technology of Petroleum Apparatus Construction Department, FSBEI HE «USPTU», Ufa, Russian Federation

e-mail: tna_ugntu@mail.ru

Исламова А.В., студент кафедры «Технологические машины и оборудование», ФГБОУ ВО «УГНТУ», г. Уфа, Российская Федерация

A.V. Islamova, Student of Technological Machines and Equipment Department, FSBEI HE «USPTU», Ufa, Russian Federation

e-mail: alena.islamova.1997@mail.ru 